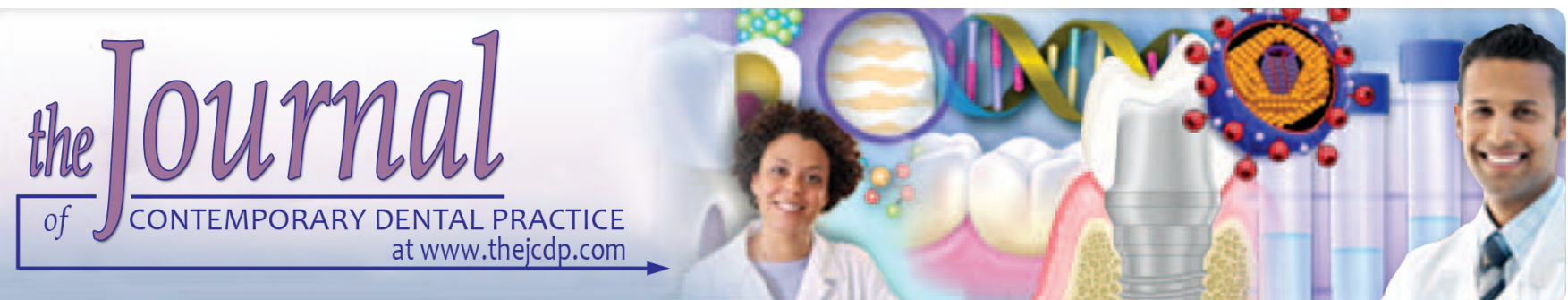

\title{
Effects of Excessive Implant Angulation on Retention of Two Types of Overdenture Attachments during Cyclic Loading
}

\author{
${ }^{1}$ Hadi Teimoori, ${ }^{2}$ Sayed S Shayegh, ${ }^{3}$ Maryam A Zavaree, ${ }^{4}$ Seyed MR Hakimaneh, ${ }^{5}$ Farinaz Khodadad, ${ }^{6}$ Shireen Shidfar, \\ ${ }^{7}$ Mohammad T Baghani
}

\begin{abstract}
Aim: This study investigated the effects of implant angulation and cyclic dislodgment on retention of Locator and Dalbo Plus attachments.

Materials and methods: Fifty pairs of acrylic blocks for five implant angulations $(0,10,20,30$ and 40 degrees) and two attachment systems (locator and Dalbo Plus $₫$; $n=5$ ) were fabricated. In each pair, one block contained two implant analogs connected to their attachments, and the other block contained matrix parts of the attachments. 1440 cycles of insertion and removal were implicated on specimens after mounting the blocks in the universal testing machine. The retention was registered at cycle numbers $1,120,360,720$, and 1440. Data were analyzed using one-way analysis of variance (ANOVA) and Duncan's multiple range test $(p \leq 0.05)$.
\end{abstract}

Results: Data analysis showed that implant angulation had significant effects on retention of both attachments at all different angles ( $p \leq 0.05)$. Dalbo Plus showed no significant differences between 30 and 40 degrees ( $p \geq 0.05$ ), but between 0 and 30 degrees, differences were significant ( $p \leq 0.05)$. Moreover, cyclic loading had significant effects on retention of both attachments at all different loading cycles ( $p \leq 0.05)$. On evaluating combined effects of cyclic loading and implant angulation on

\footnotetext{
${ }^{1}$ Department of Prosthodontics, Faculty of Dentistry, Kashan University, Kashan

${ }^{2-4}$ Department of Prosthodontics, Faculty of Dentistry, Shahed University, Tehran, Iran

${ }^{5}$ Department of Prosthodontics, Faculty of Dentistry, Qazvin University of Medical Sciences, Qazvin, Iran

${ }^{6}$ Department of Periodontics, Faculty of Dentistry, Qom University of Medical Sciences, Qom, Iran

${ }^{7}$ Department of Prosthodontics, Faculty of Dentistry, Shahid Beheshti University of Medical Sciences, Tehran, Iran

Corresponding author: Mohammad T Baghani, Daneshjou Blvd, Velenjak Ave. Faculty of Dentistry, Shahid Beheshti University of Medical Sciences,Tehran, Iran Tel.: 00989124972695, e-mail: Mtbaghani@gmail.com
}

retention, a significant decrease in retention was noted for both Locator and Dalbo Plus attachments at angulations of 0,10 , 20 degrees after 1440 cycles ( 1 year of clinical use; $p \leq 0.05$ ).

Conclusion: Both angulation and cyclic loading have negative effects on implant-supported overdentures and decrease retention over time. Furthermore, as the angle between implants increases, decrement of retention becomes more significant.

Clinical significance:Inter-implant angulation could play a significant role in overdenture retention

Keywords: Dental implants; Dental prosthesis; Implant angulation; Implant-supported Overdenture; Retention.

How to cite this article: Teimoori $\mathrm{H}$, Shayegh SS, Zavaree MA, Hakimaneh SMR, Khodadad F, Shidfar S, Baghani MT. Effects of Excessive Implant Angulation on Retention of two Types of Overdenture Attachments during Cyclic Loading The Journal of Contemporary Dental Practice, October 2018;19(10): 1221-1227.

\section{Source of support: Nil}

Conflict of interest: None

\section{INTRODUCTION}

Nowadays, implant-supported overdentures are a common treatment modality to improve function and satis faction in edentulous patients. ${ }^{1-4}$ These have proven to be a logical method to maintain oral function and to delay or eliminate future prosthodontic issues. ${ }^{5,6}$ Reportedly, insertion of implants in edentulous patients contributes toward preservation of residual ridges, improvement of masticatory parameters, and patient satisfaction. ${ }^{7,8}$ There are several types of attachment systems designed for implant-supported overdentures. ${ }^{9}$

The attachment component of an implant-retained overdenture is responsible for retention and subsequently for continuing functionality and patient satisfaction; nevertheless, there is no consensus regarding the optimal 
amount of retention. ${ }^{10}$ Andreiotelli et al. demonstrated that the least amount of appropriate retention for retaining an overdenture ranges 10 to $20 \mathrm{~N} .{ }^{11}$ There are several factors that contribute toward the retention of attachment systems: distance between implants, ${ }^{12}$ direction of forces, ${ }^{12}$ attachment's materials, ${ }^{12,13}$ attachment system's design, dimension of attachment, ${ }^{12-14}$ and angulation of implants. ${ }^{12,15}$

Numerous studies have stated that attachment systems would wear and deform during the function, thereby causing reduction or loss of retention. ${ }^{12-16}$ Retention is defined as a quality inherent in a prosthesis that acts to resist forces of dislodgement along the path of placement. ${ }^{17}$ Studies have reported a direct relationship between retention, stability, and patient satisfaction. ${ }^{18-20}$

Loosening of overdenture retentive mechanisms has been identified as the most common prosthodontic complication (33\%) in the implant-supported restorations. ${ }^{12,21}$ Failure of overdenture attachments adversely affects their function, maintenance, as well as patient satisfaction. ${ }^{22}$ Besimo et al. stated that after an appropriate number of insertion-removal cycles, attachments obtain more stable retentive properties, which better represent the post-insertion period. ${ }^{23}$

Considering the aforementioned aspects as well as the inconsistencies in available literature, this in vitro study was designed to evaluate the combined effects of implant angulation as well as cyclic insertion and removal of an overdenture on the retention of Locator and Dalbo Plus attachments. The null hypothesis was that different implant angulations and cyclic insertion and removal have no effect on the retention of attachments.

\section{MATERIALS AND METHODS}

Extended range Locator ${ }^{\circledR}$ attachment (Zest Anchors, Zest Dental Solutions, Carlsbad, California, USA) and Dalbo Plus ${ }^{\circledR}$ attachment (DIO Co., Busan, Korea) were selected for this study. The experimental design of the research included the fabrication of 100 pairs of acrylic blocks for five implant angulations (0,10, 20, 30 and 40 degrees) and two attachment systems (locator and Dalbo Plus ${ }^{\circledR} ; \mathrm{n}=10$ ). Each specimen was composed of two acrylic blocks: one block contained two implant analogs connected to their attachments, whereas the other block contained female parts of these attachments. The analogs were mounted at five different degrees by using a goniometer, with the same implant height and an interimplant distance of $23 \mathrm{~mm} .{ }^{16}$ In the other acrylic block that acted as the patients' overdentures, the matrix (female) component of the attachment was re-lined using GC self-curing acrylic.

After preparing the specimens, two relating acrylic blocks were inserted in two jaws of a universal testing machine (Zwick Roell Group, Ulm, Germany) such that the edges of the lower block were parallel to the upper edges of the machine's lower jaw. Medium-sized jaws were used. The test was conducted as specimens were impregnated with artificial saliva. ${ }^{15}$ The machine speed was set at $50 \mathrm{~mm} /$ second, similar to the speed that patients usually insert and remove their dentures. ${ }^{16}$ The rate of cyclic loading was 20 cycles/minute with an interval of 3 seconds. ${ }^{16}$ Based on the fact that a normal patient inserts and removes his/her overdenture four times a day (insertion in the morning; removal and insertion after breakfast, lunch, and dinner; and removal at nights), a tensile test was conducted on the specimens at cycles 0, 120 (equal to one month of clinical use), 360 (equal to three months of clinical use), 720 (equal to six months of clinical use), and 1440 (equal to one year of clinical use). The maximum separating force registered by the universal testing machine was considered as the retention of each specimen.

One of the Dalbo plus attachments and one of the nylon inserts were randomly selected and examined under stereomicroscope (Magnum, Olympus, India Pvt. Ltd., New Delhi, India) at $\times 40$ magnification after 0 and 1440 dislodgments.

\section{Statistical Analysis}

Results were statistically analyzed using one-way ANOVA and Duncan's multiple range test. A p-value $\leq 0.05$ was considered significant. The mean and standard deviation (SD) of both attachment's retention according to implant angulation and cyclic loading, are presented in Table 1. The methodology was reviewed, and the results were confirmed by an independent statistician.

\section{RESULTS}

The effects of the variables "implant angulations" and "cyclic loading" on retention of the Locator attachment were separately assessed first. Then, the effects of interactions between both "implant angulations" and "cyclic loading" on the retention of Locator attachments were evaluated.

The mean and SD of retention after each cycle according to implant angulations, are shown in Graphs 1 and 2 for locator and Dalbo Plus attachments respectively. Data analysis revealed that implant angulation had a significant effect on the retention of Locator attachments at all the various implant angulations ( $p \leq 0.05)$; this indicates that as implant angulation increases, the retention of Locator attachment significantly decreases. On the other hand, Dalbo Plus attachments showed no significant differences between 30 and 40 degrees ( $p \geq 0.05)$, but these differences were significant between 
Attachment's Retention of Excessively Angulated Implants

Table 1: Mean retention in locator attachment and Dalbo Plus at different implant angulations according to cyclic loading

\begin{tabular}{llllll}
\hline \multicolumn{1}{l}{ Cycle } & & & & \\
Angle & 1 & 120 & 360 & 720 & 1440 \\
\hline \multicolumn{2}{l}{ Locator attachment } & & & & \\
\hline $0^{\circ}$ & $141.81 \pm 1.37$ & $125.64 \pm 1.09$ & $100.10 \pm 0.98$ & $79.49 \pm 1.30$ & $34.69 \pm 2.06$ \\
$10^{\circ}$ & $143.90 \pm 2.52$ & $122.37 \pm 1.75$ & $96.28 \pm 1.38$ & $75.13 \pm 0.96$ & $33.19 \pm 2.08$ \\
$20^{\circ}$ & $140.32 \pm 1.42$ & $118.21 \pm 2.27$ & $90.59 \pm 1.21$ & $72.54 \pm 1.46$ & $31.46 \pm 1.83$ \\
$30^{\circ}$ & $135.77 \pm 0.89$ & $109.94 \pm 1.90$ & $87.18 \pm 1.42$ & $43.95 \pm 1.61$ & $29.95 \pm 1.80$ \\
$40^{\circ}$ & $131.01 \pm 1.38$ & $105.74 \pm 1.18$ & $82.51 \pm 1.19$ & $38.80 \pm 0.74$ & $30.13 \pm 2.06$ \\
Dalbo plus & & & & & \\
$0^{\circ}$ & $131.12 \pm 1.54$ & $129.62 \pm 1.23$ & $112.61 \pm 1.81$ & $98.33 \pm 1.61$ & $89.57 \pm 0.99$ \\
$10^{\circ}$ & $135.06 \pm 1.72$ & $127.95 \pm 0.88$ & $112.89 \pm 0.92$ & $102.04 \pm 1.45$ & $90.66 \pm 1.17$ \\
$20^{\circ}$ & $130.40 \pm 1.19$ & $126.42 \pm 0.69$ & $108.33 \pm 0.76$ & $96.17 \pm 0.85$ & $81.18 \pm 1.59$ \\
$30^{\circ}$ & $129.48 \pm 1.31$ & $125.82 \pm 1.44$ & $104.34 \pm 1.58$ & $93.14 \pm 1.66$ & $79.99 \pm 1.48$ \\
$40^{\circ}$ & $128.26 \pm 1.66$ & $124.24 \pm 1.29$ & $103.52 \pm 1.43$ & $91.84 \pm 1.54$ & $79.38 \pm 1.52$ \\
\hline
\end{tabular}

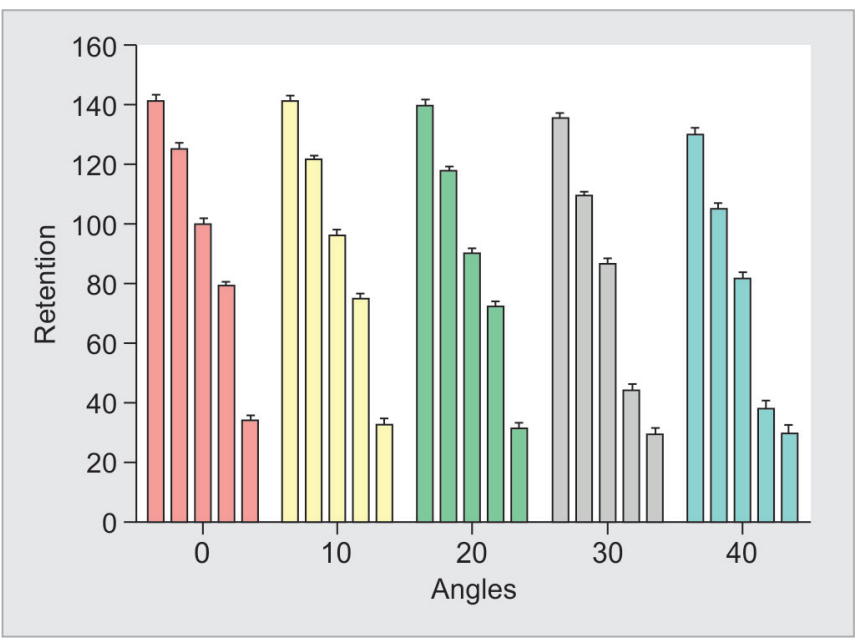

Graph 1: Mean and standard deviation of locator attachment retention at different angles with cyclic loading

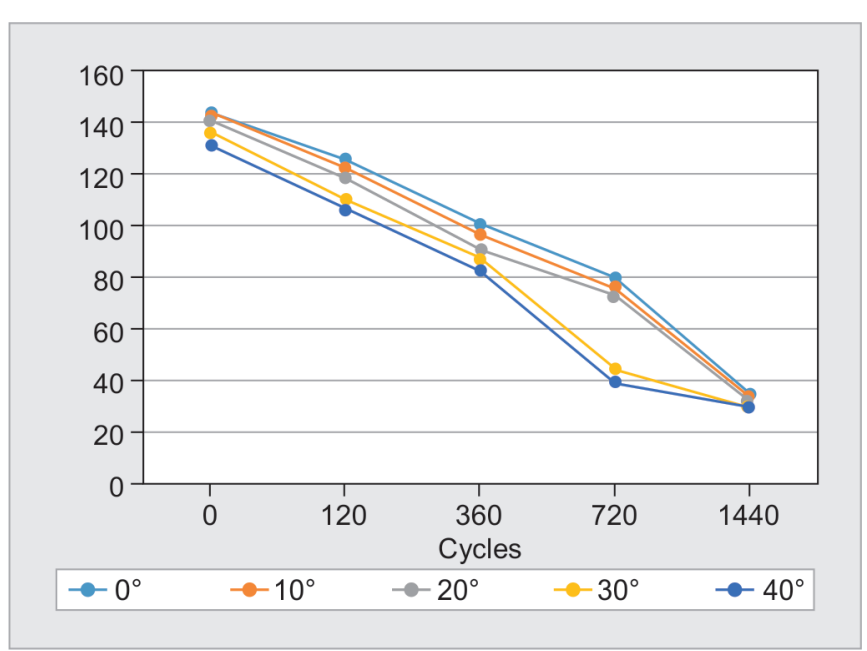

Graph 3: Mean retention of locator attachments after 1 year of simulation at different angles

0 and 30 degrees $(\mathrm{p} \leq 0.05)$, which indicates that from 0 to 30 degrees, as implant angulation increases, retention of the Dalbo Plus attachment reduces significantly, but from 30 to 40 degrees, no significant differences were noted in retention of this attachment.

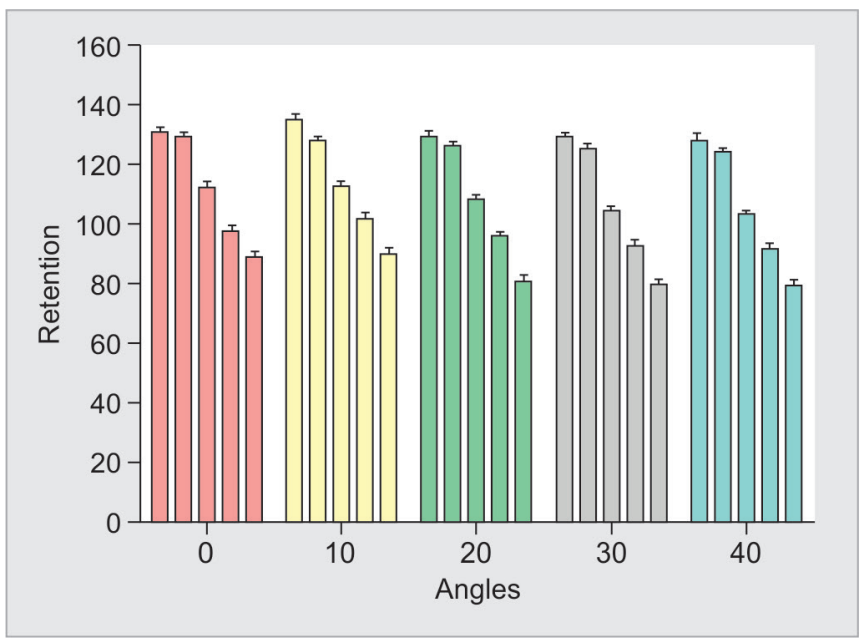

Graph 2: Mean and standard deviation of Dalbo plus retention at different angles with cyclic loading

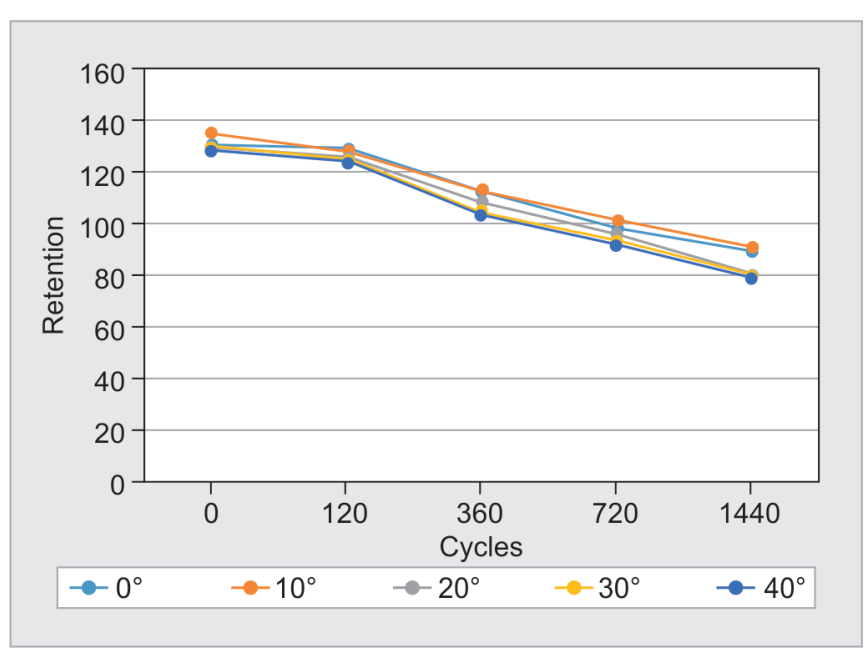

Graph 4: Mean retention of Dalbo plus after 1 year of simulation at different angles

In addition, data analysis revealed that cyclic loading had a significant effect on the retention of both attachments at all loading cycles $(p \leq 0.05)$, indicating that as the frequency of overdenture insertion and removal increases, attachment retention decreases significantly (Graphs 3 and 4). 
Moreover, when evaluating the combined effect of cyclic loading and implant angulation on retention, significant decreases were noted in retention of both Locator and Dalbo Plus attachments at angulations of 0,10 , and 20 degrees during cycle number 1440 (1 year of clinical use; $\mathrm{p} \leq 0.05$ ). Furthermore, at an implant angulation of 30 and 40 degrees, retention decreased significantly during cycle number 720 of loading ( 6 months of clinical use; $\mathrm{p} \leq 0.05$ ).

Stereomicroscope evaluation of nylon inserts after 0 and 1,440 cycles of dislodging forces (Figs 1A and B) revealed obvious deformation of nylon insert after 1,440 cycles, whereas the comparison of stereomicroscope pictures of Dalbo Plus attachment after 0 and 1,440 cycles (Figs 1C and D) showed only some degree of surface abrasions.

\section{DISCUSSION}

The present study evaluated the effects of implant angulation and cyclic dislodgement of an overdenture on the retention of two different attachment systems. The results of this study reject the null hypothesis because implant angulations, and cyclic insertion and removal, affected the retention of attachments.
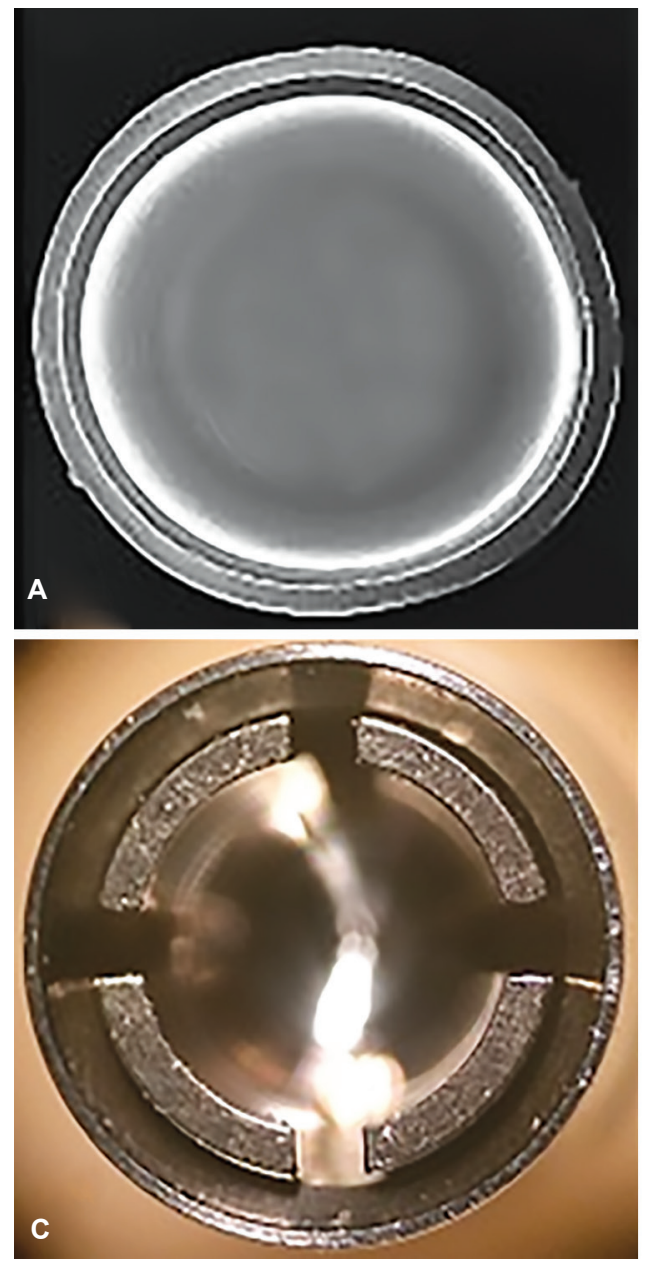

The underlying principle of using retentive implantsupported overdenture systems for treatment of edentulous patients is to increase denture retention and stability, thereby promoting masticatory functioning as well as patient comfort and compliance. ${ }^{24,25}$ Retention of overdentures has been identified as a characteristic that influences patient satisfaction. ${ }^{18,19}$ The present study was conducted to evaluate the impact of three effective factors on the retention of Locator and Dalbo Plus attachments: implant angulation, cyclic insertion and removal, as well the interaction between these two factors.

Results of this study revealed that both implant angulation and cyclic loading had significant effects on attachment retention. These results could indicate that as implant angulation increases, the amount of retention decreases significantly; this could be considered as a result of attachment design, wherein the attachments are actually designed to release maximum retention when a tensile load is applied in the vertical direction. Manufacturers of the Locator attachment claim that it has an efficacy (i.e., "efficacy of attachments") of up to 40 degrees of angulation, which means that until 40 degrees, we can still match the matrix and patrix components of
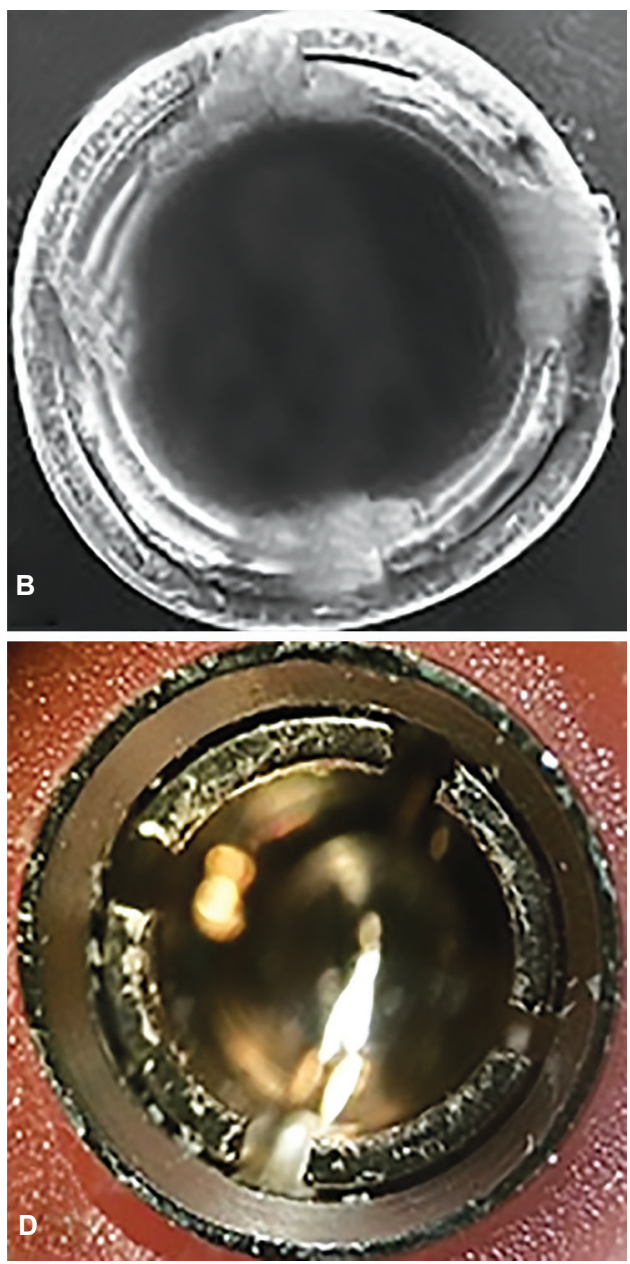

Figs 1A to D: (A) Stereomicroscope picture of nylon insert after 0 dislodging cycles $(\times 40)$; (B) Stereomicroscope picture of nylon insert after 1440 dislodging cycles (×40); (C) Stereomicroscope picture of Dalbo Plus attachment after 0 dislodging cycles (×40); (D) Stereomicroscope picture of Dalbo Plus attachment after 1440 dislodging cycles $(\times 40)$ 
the attachment, whereas in other attachments such as ball attachments, there is no such possibility. Nevertheless, the important issue is whether angulated implants have negative effects on retention of locator attachments. Results of the present study revealed that implant angulation has negative effects on attachment retention, and as the angle between two implants increases, retention decreases. However, it should be mentioned that in the Dalbo Plus group, the decrease in retention was not statistically significant between 30 and 40 degrees. However, as cycles of insertion and removal increased, the retention of both attachments decreased significantly. The retentive part of the female component in locator attachments is a nylon insert that causes frictional retention; therefore, as insertion and removal cycles increase, this nylon insert abrades and deforms and loses its efficacy (Figs 1A and B). Thus, in order to maintain the efficacy of overdentures, this nylon insert should be regularly replaced. On the contrary, since the retention of Dalbo Plus is obtained through metallic components (Fig. 1C), fatigue and attachment deformation could be the causes of decrease in retention as the number of cycles increase (Fig. 1D).

When evaluating the effects of interactions between "implant angulation" and "cyclic loading" on overdenture retention, results of the Locator attachment group showed that at 0,10 , and 20 degrees of angulation, the retention dramatically decreased at cycle number 1440, but at 30 and 40 degrees of angulation, the retention decreased significantly at cycle number 720; this indicates that when the angle between two implants increases, nylon inserts must be replaced sooner to maintain adequate retention. This interpretation could be applied to Dalbo Plus attachments as well; however, metallic components have longer durability than nylon inserts. Kobayashi et al. conducted a study to evaluate the effects of cyclic loading on retention and torque with unfastening of three types of overdenture attachments. ${ }^{16}$ The amount of retention was measured at cycles 10, 100, 1000, 5000, 10,000 , and 14,600 by using a universal testing machine. In addition, fastening torque of each specimen was measured at the beginning and end of the experiment. Results revealed that after 5000 cycles, Locator attachments had less retention than Dalbo Plus. Moreover, implant angulation of up to 12 degrees did not have any significant effects on attachment retention. Thus, it could be said that attachments whose retention systems are based on nylon components have a high sensitivity to abrasion during insertion and removal cycles. In our study as well, the retention of Locator attachments decreased after cyclic loading; however, in the Kobayashi study, implant angulation was limited to two angles alone. In 2012, Shayegh et al. conducted a study to compare the effects of various interimplant distances and cyclic dislodgment on the retention of Locator attachments. ${ }^{26}$ The results showed that as in our study, cyclic dislodgment resulted in decreased retention of the attachment.

In 2012, Atashrazm et al. conducted a study to determine the impact of inclined implants and attachments on the retention and longevity of implant-retained overdentures. ${ }^{27}$ They evaluated three different angulations: 5, 10 and 15 degrees. Results revealed no significant differences in retention between 5 and 15 degrees, but the average retention was significantly greater at 10 and 0 degrees. Based on results of this study, implant and attachment angulations affect the retention as well as longevity of overdenture attachments; i.e., the amount of wear and retention decrement will increase with every 15 degrees of angle deviation. These findings are in line with our study results. In 2009, Al-Ghafli et al. compared different implant angulations $(0,5,10,15$, and 20 degrees $)$ as well as frequent insertion and removal on the retention of Locator attachments. ${ }^{28}$ They performed frequent loading and evaluated the cycle numbers during which the retention reached $75 \%, 50 \%$, and $25 \%$ of the initial retention. Results revealed that in each angulation group, the retention decreased gradually as the frequency of insertion and removal increased. Moreover, significant differences were observed in the amount of retention at various implant angulations. Researches have proposed that an implant angulation of 5 degrees may produce perfect friction between patrix and matrix without accelerating nylon wear. Our study results regarding implant angulation and frequent loading are concordant with these results. Furthermore, in 2010, Alsabeeha et al. conducted a study to evaluate the circumstances of 1 year of clinical usage of four ball attachments comparing metallic and polymeric female parts. ${ }^{10}$ Following 1 year of clinical use, an abrasion test was conducted, and a significant decrease of 14 to $80 \%$ was noted in retention across all groups. This reduction was less for metallic components than for nonmetallic ones. The scanning electron microscope analysis revealed that metal components remained unchanged, while polymers showed marked deformation. These findings once again indicate that retention decreases in plastic attachments by frequent loading and also reinforce the results of our study. Rutkunas et al. reported that after 15000 cycles of insertion and removal, retention could be reduced to up to $21 \%$ of primary retention. ${ }^{29}$ These results are in line with results of our study, suggesting that the primary cause of decreased retention after frequent loading could be abrasion and deformity of nylon insert parts of patrix attachments.

The present in vitro study evaluated only the fatigue behavior of two attachment systems in different implant angulations. However, in vivo, the retention of the overdenture attachments than those investigated in this study. 
Other factors such as oral environment, saliva, as well as foods and beverages that a patient consumes daily, or use of denture cleaners with varying $\mathrm{pH}$ or varying chemical properties may affect the retentive properties of attachments; additional studies must be conducted to evaluate these factors.

\section{CONCLUSION}

Within the limitations of this study and based on the findings, the following conclusions may be drawn:

- By using Locator and Dalbo Plus attachments in overdentures, the retention decreases gradually as insertion and removal cycles increase.

- As angulation between the implants increases, retention of attachments markedly decreases.

\section{ACKNOWLEDGMENTS}

Authors would like to thank DIO Corp. for their support in terms of implant components.

\section{REFERENCES}

1. Heckmann SM, Heußinger S, Linke JJ, Graef F, Pröschel P. Improvement and long-term stability of neuromuscular adaptation in implant-supported overdentures. Clin Oral Implants Res. 2009;20(11):1200-1205.

2. Ueda T, Kremer U, Katsoulis J, Mericske-Stern R. Long-term results of mandibular implants supporting an overdenture: implant survival, failures, and crestal bone level changes. Int J Oral Maxillofac Implants. 2011;26(2):365-372.

3. Dudic A, Mericske-Stern R. Retention Mechanisms and Prosthetic Complications of Implant-Supported Mandibular Overdentures: Long-Term Results. Clin Implant Dent Relat Res. 2002;4(4):212-219.

4. MacEntee MI, Walton JN CNA. clinical trial of patient satisfaction and prothodontics needs with ball and bar attachments for implant retained complete overdentures: three-years results. J prosthet Dent. 2005;93:28-37. http://www.sciencedirect.com/science/article/pii/ S0022391304006882. Accessed December 23, 2017.

5. Kordatzis K, Wright PS, Meijer HJ a. Posterior mandibular residual ridge resorption in patients with conventional dentures and implant overdentures. Int J Oral Maxillofac Implants. 2003;18(3):447-452. http://www.ncbi.nlm.nih. gov/p. Accessed December 23, 2017.

6. Tallgren A. The continuing ridges reduction denture study of the residual wearers : covering alvealar in complete 25 years. J Prosthet Dent. 1972;27(2):120-132.

7. Awad M a, Lund JP, Shapiro SH, et al. Oral health status and treatment satisfaction with mandibular implant overdentures and conventional dentures: a randomized clinical trial in a senior population. Int J Prosthodont. 2003;16(4):390-396.

8. Stellingsma K, Slagter AP, Stegenga B, Raghoebar GM, Meijer HJA. Masticatory function in patients with an extremely resorbed mandible restored with mandibular implant-retained overdentures: Comparison of three types of treatment protocols. J Oral Rehabil. 2005;32(6):403-410.
9. Stewart B, Edwards R. Retention and wear of precision type attachments. J Prosthet Dent. 1983;49:28-34. http://www. sciencedirect.com/science/article/pii/0022391383902330. Accessed December 23, 2017.

10. Alsabeeha, Nabeel HM; Payne, Alan GT, Swain MV. Attachment Systems for Mandibular Two-Implant Overdentures: A Review of In Vitro Investigations on Retention an Wear Features. J Chem Inf Model. 2013;53(9):1689-1699.

11. Andreiotelli M, Att W, Strub JR. Prosthodontic complications with implant overdentures: a systematic literature review. Int J Prosthodont 2010;23(3):195-203.

12. Goodacre CJ, Bernal G, Rungcharassaeng K, Kan JYK. Clinical Complication with Implants and Implant Protheses. J Prosthet Dent. 2003;90(2):121-132.

13. Fromentin $\mathrm{O}$, Picard $\mathrm{B}$, Tavernier B. In vitro study of the retention and mechanical fatigue behavior of four implant overdenture stud-type attachments. Pract Periodontics Aesthet Dent. 1999;11(3):391-7; quiz 398. http://europepmc. org/abstract/med/10379298. Accessed December 23, 2017.

14. Rutkunas V, Mizutani $\mathrm{H}$, Takahashi $\mathrm{H}$. Influence of attachment wear on retention of mandibular overdenture. J Oral Rehabil. 2007;34(1):41-51.

15. Aroso C, Silva AS, Ustrell R, et al. Effect of abutment angulation in the retention and durability of three overdenture attachment systems: An in vitro study. J Adv Prosthodont. 2016;8(1):21.

16. Kobayashi M, Srinivasan M, Ammann P, et al. Effects of in vitro cyclic dislodging on retentive force and removal torque of three overdenture attachment systems. Clin Oral Implants Res. 2014;25(4):426-434.

17. The glossary of prosthodontic terms. J Prosthet Dent. 1999;81(1):39-110. http://www.ncbi.nlm.nih.gov/ pubmed/10200082. Accessed December 23, 2017.

18. Naert I, Quirynen M, Theuniers G, van Steenberghe D. Prosthetic aspects of osseointegrated fixtures supporting overdentures. A 4-year report. J Prosthet Dent. 1991;65(5):671-680.

19. Feine JS, de Grandmont P, Boudrias P, et al. Within-subject Comparisons of Implant-supported Mandibular Prostheses Choice of Prosthesis 1994. J Dent Res. 1994;73(5):11051111.

20. Stoker G, Wismeijer D, van Waas MAJ. An Eight-year Follow-up to a Randomized Clinical Trial of Aftercare and Cost-analysis with Three Types of Mandibular Implantretained Overdentures. J Dent Res. 2007;86(3):276-280.

21. Chaffee N, Felton D, Cooper L, Palmqvist U, Smith R. Prosthetic complication in an implant-retained mandibular overdenture population: Initial analysis of a prospective study. J Prosthet Dent. 2002;87(1):40-44. http://www. sciencedirect.com/science/article/pii/S0022391302377989. Accessed December 23, 2017.

22. Payne AG, Solomons YF. Mandibular implant-supported overdentures: a prospective evaluation of the burden of prosthodontic maintenance with 3 different attachment systems. Int J Prosthodont. 2000;13(3):246-253.

23. Besimo CE, Guarneri A. In vitro retention force changes of prefabricated attachments for overdentures. J Oral Rehabil. 2003;30(7):671-678.

24. Doundoulakis JH, Eckert SE, Lindquist CC, Jeffcoat MK. The implant-supported overdenture as an alternative to the complete mandibular denture. J Am Dent Assoc. 2003;134(11):1455-1458. 
25. Cune MS, van Kampen FMC, van der Bilt A, Bosman F. Patient satisfaction and preference with magnet, bar-clip, and ball-socket retained mandibular implant overdentures: a cross-over clinical trial. Int J Prosthodont. 2005;18(2):99105.

26. Shayegh SS, Hakimaneh SMR, Baghani MT, et al. Effect of interimplant distance and cyclic loading on the retention of overdenture attachments. J Contemp Dent Pract. 2017;18(11):1078-1084.

27. Atashrazm P. The Influence of Inclined Implants and Attachments on the Retention and Longevity of Implant-
Retained Overdentures: An In Vitro Study. J Dent Shiraz Univ Med Scien. 2012;13(3):90-96. http://dentjods.sums. ac.ir/index.php/JDSUMS/article/view/40. Accessed December 23, 2017.

28. Al-Ghafli S, Michalakis K, Hirayama H, Kang K. The in vitro effect of different implant angulations and cyclic dislodgement on the retentive properties of an overdenture attachment system. J prosthet Dent. 2009;102(3):140-147.

29. Rutkunas V, Mizutani H, Takahashi H, Iwasaki N. Wear simulation effects on overdenture stud attachments. Dent Mater J. 2011;30(6):845-853. 